\title{
Analysis and suggestions on medical educators' roles
}

\author{
Meeran Joo', Yoo-mi Chae ${ }^{2}$, Man-Sup Lim³ and Seok-gun Park',* \\ ${ }^{1}$ College of Liberal Arts, Dankook University, ${ }^{2}$ Department of Medical Education, Dankook University College \\ of Medicine, Cheonan, ${ }^{3}$ Department of Medical Education, College of Medicine, Hallym University, Chuncheon, \\ and ${ }^{4}$ Dankook University College of Medicine, Cheonan, Korea
}

Purpose: This study aimed to investigate the differences in the perception between professors and students regarding medical educators' roles and discuss their desirable roles.

Methods: A survey was administered to 116 professors and 379 students of the medical colleges from Dankook University and Hallym University. The subjects were given a self-created questionnaire designed to measure their perception of medical educators' roles.

Results: First, "student performance management" for professors and "teaching skill development" for students were recognized as the most essential medical educators' role. Second, females students perceived the roles to be more important than males in eight of 10 roles.

Conclusion: First, "student performance management" for professors and "teaching skill development" for students were recognized as the most essential medical educators' role. Second, females students perceived the roles to be more important than males in eight of 10 roles.

Key Words: Medical educators' roles, Perception on medical educators' roles, Difference between professors and students, Medical educators

\section{Introduction}

According to the data collected by the Korean Society of Medical Education in 2017, 40 medical schools nationwide had medical education supporting institutions, including full-time or part-time medical educators under various names, such as Department of Medical Education, Office of Medical Education, Medical Education Unit, or Medical Education Center, and so forth. In this study, medical educators indicate the professors who are involved in or work for the these medical education supporting institutions. The medical educators' roles are decided according to the direction pursued by the dean or immersed in preparation for accreditation evaluation [1]. Therefore, it is needed to clearly understand the roles of medical educators to create a professional identity as a medical educator, and this will be a prerequisite for achieving excellence in the medical education.

However, there have been only a few studies examining the differences in perceptions between professors and students about the role of medical educators with some examples as a study on gaps in the
Received: August 7, 2021 • Revised: September 2, 2021 • Accepted: October 1, 2021 Corresponding Author: Yoo-mi Chae (https://orcid.org/0000-0003-1071-6099) Department of Medical Education, Dankook University College of Medicine, 119 Dandae-ro, Dongnam-gu, Cheonan 31116, Korea

Tel: +82.41.550.3291 Fax:+82.41.556.6461 email: 12070108@dankook.ac.kr

*Seok-gun Park is an emeritus professor at Dankook University College of Medicine.
Korean J Med Educ 2021 Dec; 33(4): 411-417

https://doi.org/10.3946/kjme.2021.209

eISSN: 2005-7288

(C) The Korean Society of Medical Education. All rights reserved. This is an open-access article distributed under the terms of the Creative Commons Attribution Non-Commercial License (http:// creativecommons.org/licenses/by-nc/3.0/), which permits unrestricted non-commercial use, distribution, and reproduction in any medium, provided the original work is properly cited. 
perception of medical students' professionalism between students and professors [2], and differences in perception between medical residents and faculty members on a resident's 80-duty hour regulation [3]. While there have been studies investigating differences in perceptions between students and professors, their topics were limited to focus on the lecture evaluation system or evaluation of teaching competency. The ratio of female doctors among all doctors in the past 20 years has increased by about $13 \%$, from $22.0 \%$ to $35.4 \%$ [4,5]. Thus, medical educators should pay attention to the differences between the genders, especially in females.

Therefore, while the fundamental framework has been built up within a relatively short period, it is now time to consider desirable roles that medical educators have in medical schools. In this research, the questions are as follows. First, what are the primary roles of medical educators recognized by the professors of clinical and scientist educators and medical students? Second, are there any differences in perceptions by gender of students?

\section{Methods}

\section{Participants}

The survey for Dankook University was conducted in April 2016 and for Hallym University in November for 1 month each, and the questionnaires were distributed and collected online. Finally, a total of 116 professors and 379 students participated in this study, excluding incomplete responses. 44 professors at Dankook University and 72 at Hallym University responded. For the students, 140 at Dankook University and 239 at Hallym University responded.

\section{Questionnaire}

First, the roles of medical education-related institutions were collected from the homepage of 40 medical colleges nationwide. Based on the goals and contents, the questionnaire was initially created by the first researcher and was then reviewed by the two other authors to check for the appropriateness of the questions. Afterward, to check whether students understood the questions, the preliminary survey was given to two students from each grade level, and finally revised based on their answers. The final questionnaire consisted of 31 questions. Respondents were asked to choose one answer from 1 (not necessary at all) to 5 (very necessary) for each question, depending on how important they thought the role of a medical educater.

\section{Statistical analysis}

T-test and chi-square test were carried out to compare the difference in perceptions between professors and students on medical educators' roles and demographic characteristics.

\section{Ethics statement}

This study was approved by the Institutional Review Board (IRB) of Dankook University (approval no., DKU-2021-02-032). The requirement for informed consent from individual participants was omitted.

\section{Results}

\section{Demographic characteristics}

There was no statistically significant difference between the two university professors' gender, age, subspecialty, and duration of employment, and whether 


\begin{tabular}{|c|c|c|c|c|c|c|}
\hline \multirow{2}{*}{ Characteristic } & \multicolumn{3}{|c|}{ Professor } & \multicolumn{3}{|c|}{ Student } \\
\hline & D & $\mathrm{H}$ & $\mathrm{p}$-value & D & $\mathrm{H}$ & p-value \\
\hline \multicolumn{7}{|l|}{ Gender } \\
\hline Male & $34(77.3)$ & $55(76.4)$ & & $98(70.0)$ & $174(72.8)$ & \\
\hline Female & $10(22.7)$ & $17(23.6)$ & 0.913 & $42(30.0)$ & $65(27.2)$ & 0.558 \\
\hline Age (yr) & $46.7 \pm 6.5$ & $45.9 \pm 7.2$ & 0.577 & $22.8 \pm 1.6$ & $23.5 \pm 1.5$ & $<0.001^{* * *}$ \\
\hline \multicolumn{7}{|l|}{ Professors of ${ }^{\mathrm{al}}$} \\
\hline Basic science & $12(27.3)$ & $10(14.0)$ & & - & - & \\
\hline Medical part ${ }^{b /}$ & $23(52.3)$ & $42(59.2)$ & & - & - & \\
\hline Surgical part ${ }^{\mathrm{cl}}$ & $9(20.5)$ & $19(26.8)$ & 0.208 & - & - & \\
\hline \multicolumn{7}{|c|}{ Duration of employment $(y r)^{a)}$} \\
\hline$>6$ & $9(22.0)$ & $26(36.6)$ & & - & - & \\
\hline $7-15$ & $21(51.2)$ & $23(32.4)$ & & - & - & \\
\hline$<16$ & $11(26.8)$ & $22(31.0)$ & 0.117 & - & - & \\
\hline \multicolumn{7}{|c|}{ Involved in medical education ${ }^{\mathrm{al}, \mathrm{dl}}$} \\
\hline Yes & $32(74.4)$ & $46(63.9)$ & & - & - & \\
\hline No & $11(25.6)$ & $26(36.1)$ & 0.242 & - & - & \\
\hline \multicolumn{7}{|l|}{ Grade } \\
\hline Grade 1 & - & - & & $29(20.7)$ & 44 (18.3) & \\
\hline Grade 2 & - & - & & $40(28.6)$ & $43(17.9)$ & \\
\hline Grade 3 & - & - & & 37 (26.4) & 76 (31.7) & \\
\hline Grade 4 & - & - & & 34 (24.3) & 77 (32.1) & 0.057 \\
\hline \multicolumn{7}{|c|}{ Overall satisfaction on curriculum } \\
\hline Good & - & - & & $121(86.4)$ & 204 (85.3) & \\
\hline
\end{tabular}

Data are presented as number $(\%)$ or mean \pm standard deviation.

D: Dankook University, H: Hallym University.

${ }^{* * *} p<0.001$ from t-test. ${ }^{a}$ Excluding missing data. ${ }^{b /}$ Internal medicine, family medicine, and so forth. ${ }^{c \mid}$ General surgery, plastic surgery, and so forth. ${ }^{\text {dl }}$ Instruction, committee activities, evaluation, or accreditation.

Table 2. The Difference of Perception on Medical Educators' Roles between Professors and Students

\begin{tabular}{|c|c|c|c|c|}
\hline No. & Roles of medical educators & Professors & Students & p-value \\
\hline \multirow[t]{4}{*}{1} & Student performance management ${ }^{* *}$ & 4.16 & 3.74 & $<0.001$ \\
\hline & Developing of student consultation program ${ }^{* * *}$ & 4.09 & 3.69 & $<0.001$ \\
\hline & Developing of evaluation methods for learning achievement*** & 4.20 & 3.62 & $<0.001$ \\
\hline & Monitoring of doctor's licensing examination** & 4.17 & 3.91 & 0.006 \\
\hline \multirow[t]{6}{*}{2} & Teaching skill development** & 4.15 & 3.97 & 0.009 \\
\hline & Developing programs for improving teaching skill & 4.08 & 4.15 & 0.429 \\
\hline & Evaluating teaching skill & 4.14 & 4.11 & 0.732 \\
\hline & Providing information on teaching skill improvement** & 4.20 & 3.93 & 0.004 \\
\hline & Developing teaching method (i.e., TBL, PBL) ${ }^{* * *}$ & 4.08 & 3.74 & $<0.001$ \\
\hline & Planning program for teaching competency improvement ${ }^{* * *}$ & 4.28 & 3.89 & $<0.001$ \\
\hline \multirow[t]{5}{*}{3} & Curriculum development ${ }^{* *}$ & 4.14 & 3.87 & $<0.001$ \\
\hline & Planning of curriculum*** & 4.14 & 3.73 & $<0.001$ \\
\hline & Evaluating of curriculum ${ }^{* *}$ & 4.25 & 3.97 & $<0.001$ \\
\hline & Supporting clinical training curriculum & 4.07 & 3.98 & 0.302 \\
\hline & Providing information for curriculum development** & 4.09 & 3.80 & 0.001 \\
\hline \multirow[t]{3}{*}{4} & Medical education accreditation $* * *$ & 4.13 & 3.83 & $<0.001$ \\
\hline & Collecting and managing of medical education-related database ${ }^{* * *}$ & 4.09 & 3.76 & $<0.001$ \\
\hline & Supporting for accreditation evaluation of medical school ${ }^{* *}$ & 4.18 & 3.89 & 0.001 \\
\hline
\end{tabular}




\begin{tabular}{|c|c|c|c|c|}
\hline No. & Roles of medical educators & Professors & Students & $\mathrm{p}$-value \\
\hline \multirow[t]{3}{*}{5} & Medical education research ${ }^{* *}$ & 3.97 & 3.77 & 0.021 \\
\hline & Training of researchers & 3.91 & 3.79 & 0.173 \\
\hline & researching on medical education ${ }^{* *}$ & 4.03 & 3.75 & 0.003 \\
\hline \multirow[t]{4}{*}{6} & Medical education support** & 3.97 & 3.77 & 0.011 \\
\hline & Supporting the committee of $\mathrm{PBL}^{* * *}$ & 3.87 & 3.53 & $<0.001$ \\
\hline & Supporting the committee of OSCE & 4.01 & 4.01 & 0.993 \\
\hline & Supporting the committee of curriculum development* & 4.02 & 3.80 & 0.011 \\
\hline \multirow[t]{4}{*}{7} & Social and humanistic medicine ${ }^{* *}$ & 3.88 & 3.53 & $<0.001$ \\
\hline & Operating medical humanities course ${ }^{* * *}$ & 3.72 & 3.36 & $<0.001$ \\
\hline & Developing of health communication teaching model ${ }^{*}$ & 3.77 & 3.52 & 0.011 \\
\hline & Developing student supporting program (i.e., humanism) ) $^{* * *}$ & 4.16 & 3.72 & $<0.001$ \\
\hline \multirow[t]{2}{*}{8} & Doctor training & 3.86 & 3.96 & 0.320 \\
\hline & Monitoring the supplement of medical doctor & 3.86 & 3.96 & 0.320 \\
\hline \multirow[t]{3}{*}{9} & Student selection policy & 3.82 & 3.71 & 0.188 \\
\hline & Evaluating of student selection policy & 3.83 & 3.73 & 0.265 \\
\hline & Developing of student selection method & 3.81 & 3.68 & 0.143 \\
\hline \multirow[t]{4}{*}{10} & Graduate medical education (i.e., intern, resident) ${ }^{* *}$ & 3.54 & 3.76 & 0.006 \\
\hline & Developing of student internships & 3.51 & 3.66 & 0.111 \\
\hline & Monitoring graduate medical education program ${ }^{* *}$ & 3.47 & 3.77 & 0.004 \\
\hline & Providing information on graduate medical education* & 3.65 & 3.87 & 0.027 \\
\hline
\end{tabular}

The level of perception on medical educators' roles was described using a 5-point Likert scale.

TBL: Task-based learning, PBL: Problem-based learning, OSCE: Objective structured clinical examination.

${ }^{*} \mathrm{p}<0.05 .{ }^{* *} \mathrm{p}<0.01 .{ }^{* * *} \mathrm{p}<0.001$ from t-test.

\section{Fig. 1. Difference of Perception on Medical Educators' Roles by Gender of Students}
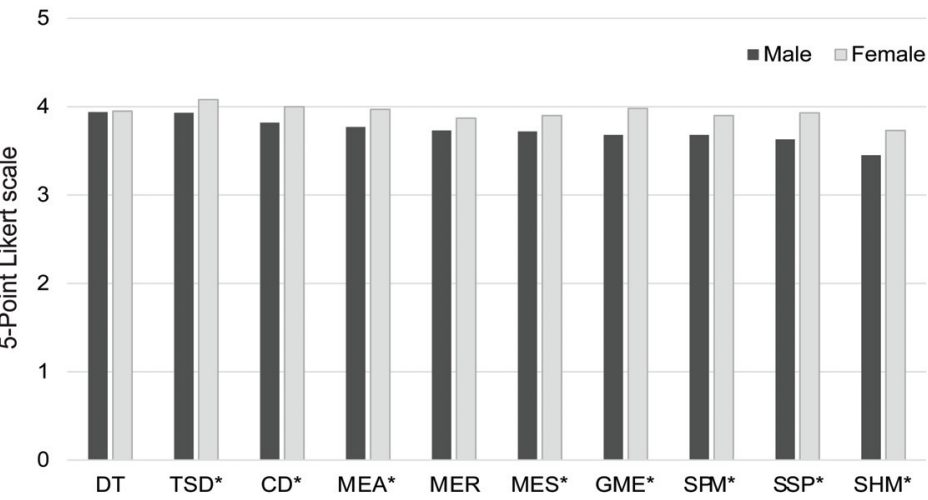

Medical educators' roles

The level of perception on medical educators' roles was described using a 5-point Likert scale. DT: Doctor training, TSD: Teaching skill development, CD: Curriculum development, MEA: Medical education accreditation, MER: Medical education research, MES: Medical education support, GME: Graduate medical education (i.e., intern, resident), SPM: Student performance management, SSP: Student selection policy, SHM: Social and humanistic medicine. ${ }^{*} \mathrm{p}<0.05$. from t-test.

they were involved in medical education. The average age of Dankook University and Hallym University college students was 22.8 and 23.5, respectively, which was statistically significant. There was no statistical difference in students' gender, grade level, and satisfaction with the entire curriculum (Table 1).

\section{Primary roles of medical educators per- ceived by professors and students}

The Cronbach's $\alpha$ value of the 31 items was high at 
0.943. As a result of factor analysis for 31 items, 28 items were ultimately categorized into 10 factors, excluding three items with a factor loading of less than 0.4.

Professors perceived the roles 1 through 7 and 9 to be more important than students and the differences were statistically significant except roles 8 and $9(\mathrm{p}<0.05)$ (Table 2). Professors perceived "student performance management" as the most important while students perceived "teaching skill development" as the most important. Notably, students regarded "graduate medical education" as the 6th most important factor while professors recognized it as the least important factor. Among items students perceived the item "developing programs for improving teaching skill” as the most important although professors ranked it low (13th), and the professor recognized "developing of evaluation methods for learning achievement" as the third most important, whereas the student showed a very low recognition (25th).

\section{Primary roles of medical educators per- ceived by gender of students}

For students, females perceived the roles to be more critical than males in eight of 10 roles, and the differences were statistically significant (Fig. 1).

\section{Discussion}

In this study, the two groups of professors and students were asked to respond to the same questionnaire to investigate the potential differences in perception of medical educators' roles.

Students perceived seven of 10 roles to be less critical than professors on medical educators' roles. Therefore, it is necessary to make efforts to deal with the student's low level of perception, and it is strongly advised that medical educators increase opportunities to have regular and consistent interaction with students to grasp the students' needs and figure out their academic levels.

Female students perceived medical educators' roles as more important than males, and the results were statistically significant. In general, female medical students report a higher level of anxiety than male students [6-9] and have significantly higher stress related to "learning the new curriculum" and "assessment", stressor related to confidence in performance [10].

In this study, professors perceived "student performance management" and "teaching skill development" as the two most crucial roles of medical educators. On the other hand, students expressed the highest demands for "teaching skill development", especially for the items of "developing programs for improving teaching skill" and "evaluating teaching skill". Similarly, in the study of Lee and Yang [11], who indicated that among the qualities of medical education, students said the role of professors is important while professors said that the curriculums (i.e., education purpose, content, and so forth) are more important. Aligning with these results, this study indicates that students showed high interest and demand in the professors' competency. Choi and Jo [12] noted that professors' competency could change the learning environment to reinforce learning accomplishment, so it is essential to improve the quality of education. Therefore, medical educators should develop teaching competency to meet students' demands to improve education contents and teaching skills.

Students are very interested in "doctor training" and "graduate medical education", which must be directly related to their future. In contrast, the professor had a relatively low interest in this role, which leads this result to show that professors are confining their roles to undergraduate education. A general idea of medical education encompasses Basic Medical Education, 
Graduate Medical Education, and Continuous Professional Development, and all medical schools in Korea are linked to university hospitals. However, current medical education is conducted separately in each significant unit or individual course. Therefore, medical educators can play a bridge role in linking professors, students, and hospitals for comprehensive medical education, ranging from educating undergraduate students and training them to meet hospitals' requirements to educate interns and residents after graduating.

It was an opportunity to re-examine areas where medical educators should focus their capabilities, abilities, or roles on, such as the areas where professors or students are less interested or where difference was shown between two groups. The clear communication of the medical educators' roles, well-defined expectations and organizationally appropriate boundaries are important to combat lingering feelings of insecurity around identity and legitimacy in both individuals and the medical education community [13]. Based on these findings, the roles of medical educators are to be suggested.

First, medical educators should build practical and sustainable programs to develop teaching-learning methods that both professors and students consider necessary. Second, both professors and students each value only limited aspects of the quality of medical education, and there is a gap of understanding between the two groups. Specifically, professors are less interested in faculty development, while students are less interested in student performance management. In addition, students' perception of medical education is generally low. Therefore, medical educators should establish direct channels to communicate with students while compromising the professors' and students' needs. Third, students are highly interested in "doctor training" and "graduate medical education". Therefore, medical educators can also play a bridge role in linking professors, students, and hospitals for comprehensive medical education, ranging from educating undergraduate students and training them to meet hospitals' requirements to educating interns and residents after graduating. Fourth, medical educators must be sensitive to gender differences.

This study has a few limitations. First, this study was conducted on only two universities, which may limit generalization. Second, the roles of medical educators in the questionnaire are not consensus-driven by experts. However, they were collected and organized from the websites of medical colleges across the country. Third, although there was a difference in the response rates of the professors between the two medical schools, the differences in terms of gender and age were not statistically significant, so it would not affect the results.

In conclusion, medical educators need to plan and develop realistic and specific curricula, taking into account the needs of both professors and students, and make the best decisions for the whole process of education, training, and development.

\section{ORCID:}

Meeran Joo: https://orcid.org/0000-0002-1766-2110; Yoo-mi Chae: https://orcid.org/0000-0003-1071-6099; Man-Sup Lim: https://orcid.org/0000-0001-9222-2740; Seok-gun Park: https://orcid.org/0000-0001-5824-6298 Acknowledgements: None.

Funding: No financial support was received for this study.

Conflicts of interest: No potential conflict of interest relevant to this article was reported.

Author contributions: YMC: conception or design of the work, data collection, data analysis and interpretation. MRJ, SGP: drafting the article. SGP: critical revision of 
the article. MSL: data collection.

\section{References}

1. Jeon WT. New challenges for medical education. In: Jeon WT, ed. Future of Medical Education. Seoul, Korea: Pakyoungsa; 2016:13-15.

2. Hur Y. Are there gaps in the perception of medical students' professionalism between medical students and professors? Korean J Med Educ. 2008;20(3):209-217.

3. Han ER, Chung EK. The perception of medical residents and faculty members on resident duty hour regulation. Korean J Med Educ. 2020;32(1):67-72.

4. Ministry of Health and Welfare. Health and welfare statistical year book 2012. Sejong, Korea: Ministry of Health and Welfare; 2012.

5. Ministry of Health and Welfare. Health and welfare statistical year book 2020. Sejong, Korea: Ministry of Health and Welfare; 2020.

6. Notman MT, Salt P, Nadelson CC. Stress and adaptation in medical students: who is most vulnerable? Compr Psychiatry. 1984;25(3):355-366.

7. Sheets KJ, Gorenflo DW, Forney MA. Personal and behavioral variables related to perceived stress of secondyear medical students. Teach Learn Med. 1993;5(2):
90-95.

8. Hayes K, Feather A, Hall A, et al. Anxiety in medical students: is preparation for full-time clinical attachments more dependent upon differences in maturity or on educational programmes for undergraduate and graduate entry students? Med Educ. 2004;38(11):1154-1163.

9. Dahlin ME, Runeson B. Burnout and psychiatric morbidity among medical students entering clinical training: a three year prospective questionnaire and interview-based study. BMC Med Educ. 2007;7:6.

10. Moffat KJ, McConnachie A, Ross S, Morrison JM. First year medical student stress and coping in a problembased learning medical curriculum. Med Educ. 2004; 38(5):482-491.

11. Lee MS, Yang EB. The quality of medical education and certification evaluation program. Korean Med Educ Rev. 1999;1(1):55-74. http://www.kmer.or.kr/pds/journal/thesis /20170222162149-8C3LJ.pdf. Accessed July 10, 2021.

12. Choi MS, Jo HY. A study on teacher competency difference perceived by teachers and learners: focusing on S university. J Learn Cent Curric Instr. 2020;20(2): 1353-1373.

13. Browne J, Webb K, Bullock A. Making the leap to medical education: a qualitative study of medical educators' experiences. Med Educ. 2018;52(2):216-226. 